\title{
REFLEXÕES ACERCA DA ASSISTÊNCIA DE ENFERMAGEM E O DISCURSO DE HUMANIZAÇÃO EM TERAPIA INTENSIVA
}

\author{
Reflections Concerning the Assistance of Nursing and \\ the Speech of Humanization in Intensive Therapy \\ Reflexiones Referentes a la Ayuda de Enfermería y el \\ Discurso de la Humanización en Terapia Intensiva
}

\section{Resumo}

Este estudo é uma reflexão que objetiva buscar como produção científica de enfermagem o cuidado que envolve o uso de tecnologias/máquinas em unidades de terapia intensiva, a partir do entendimento acerca do cuidado, tecnologia e humanização, e as implicações para a prática de cuidar em unidades tecnológicas de clientes críticos. Traz reflexões acerca da temática "humanização em terapia intensiva", a partir do aprofundamento das leituras e discussão dos dados, na construção de uma tese em curso na Escola Anna Nery, cujo objeto de investigação é "o significado do cuidado em unidades de terapia intensiva". Verificou-se que qualquer que seja a reflexão acerca das práticas de cuidar em terapia intensiva que desconsidere seus conceitos, o contexto e suas bases possibilitadoras poderá incorrer em equívocos comprometedores, capazes de se constituírem obstáculos epistemológicos.

Palavras-chave: Cuidados de Enfermagem. Tecnologia. Unidades de Terapia Intensiva. Enfermagem.

\begin{abstract}
This study is a reflection that objective to search as scientific production of nursing the care that involves the use of technologies and machines in units of intensive therapy, from the agreement concerning the care, technology and humanization, and the implications for the practical one to take care in technological units together the critical patients. Brings reflections about the thematic "humanization in units of intensive therapy", from the deepening of the readings and quarrel of the data in the construction of a Thesis in course in the Anna Nery School, whose object of inquiry is "the meaning of the care in units of intensive therapy". Was verified that that is the reflection concerning the practical ones to take care of in intensive therapy that disrespects its concepts, the context and its possibly bases, will be able to incur into mistakes to compromise, capable of if constituting epistemological obstacles.
\end{abstract}

Keywords:

Nursing Care. Technology. Intensive Care Units. Nursing.

\section{Resumen}

El estudio es una reflexión la cual objetiva buscar como producción científica de enfermeria el cuidado que implica el uso de tecnologias y de maquinas en unidades de la terapia intensiva, del referente cuidado, la tecnología y a la humanización, y sus implicaciones para el práctico de cuidar en unidades tecnológicas de clientes críticos. Está es una reflexión referente a "humanización en terapia intensiva", a partir de las lecturas y discusión de los datos, en la construcción de una tesis de doutorado en curso en la Escuela de Enfermeria Ana Nery, cujo objeto de la investigación es el significado del cuidado en unidades del terapia intensiva. Fue verificado cuales sean las reflexiones referente a las prácticas de cuidar en la terapia intensiva que no considera sus conceptos, el contexto y sus bases, posiblemente, podrá incurrir en errores para comprometerse, capaz de constituir obstáculos epistemologicos.

Palabras clave: Atención de Enfermería. Tecnologia. Unidades de Terapia Intensiva. Enfermería. 


\section{INTRODUÇÃO}

Na tentativa de conceituar o cuidado, devemos considerar, entre outras coisas, que ele é parte integrante da vida humana, e que nenhuma vida pode subsistir sem ele ${ }^{1}$.

Nas últimas duas décadas o cuidado tem merecido a atenção de um número significativo de estudiosos, pesquisadores e teóricos de outras áreas de conhecimento, cada qual procurando trazer suas contribuições no sentido de possibilitar uma melhor compreensão acerca de seus diferentes conceitos e significados.

Aproximando-nos um pouco mais do cotidiano das terapias intensivas, acreditamos que em função de sua especificidade, a assistência de enfermagem nestas unidades, traz em seu escopo algo que a diferencia outras.

Nesta perspectiva, entendemos que no contexto destas unidades, as máquinas de suporte de vida, como ventiladores mecânicos, balões intra-aórticos etc., são tecnologias que exigem da enfermagem habilidades e competências para cuidar que parecem ser o "divisor de águas" entre o cuidado prestado na terapia intensiva e em outras unidades.

As reflexões deste artigo emergem de uma experiência primeira fruto de uma investigação de Tese de Doutorado concluída em 2006 que teve como objeto de investigação, problemas relacionados ao significado do cuidado de enfermagem em terapia intensiva a partir do uso de tecnologias.

A base teórica que sustentará nossas reflexões será a multirreferencialidade ${ }^{2}$ e se apoiará em teóricos de enfermagem que têm discutido o cuidado, além de teóricos que tratam da questão da técnica e da tecnologia, bem como da humanização.

\section{CONTEXTUALIZANDO O CUIDADO E A TECNOLOGIA DE TERAPIA INTENSIVA}

Na busca de uma melhor contextualização do cuidado em terapia intensiva e de suas tecnologias, nos apoiamos em alguns teóricos que pensam o cuidado como uma peculiaridade do humano e condição primeira para a sua existência.

Desta forma, precisamos considerar que os valores humanísticos e artísticos, o desenvolvimento e estimulação da fé-esperança, a sensibilidade e a ajuda-confiança são aspectos relevantes e que precisam estar presentes no processo de cuidar, possibilitando tornar-se holístico ${ }^{3}$.

Por entendermos o cuidado de enfermagem como um complexo construto, acreditamos que ele possa ter diferentes dimensões, o que não significa dizer que isso possa inviabilizar o entendimento de que ele é humano, ainda que tenhamos que nos apropriar de tecnologias e máquinas para cuidar.

A apropriação de tecnologias, em particular aquelas entendidas como duras ${ }^{4}$, é considerada por Coelho ${ }^{5}$ como fundamental para cuidar e assistir, pois elas contribuem sobremaneira na ampliação da capacidade natural de sentir, embora exija da enfermagem um alto grau de qualificação profissional.

Desta forma, as unidades de terapia intensiva são consideradas locais especiais que demandam um alto grau de especialização do trabalho da equipe de enfermagem. Exigem do trabalhador um treinamento adequado, uma afinidade para atuar em unidades fechadas e uma resistência diferenciada dos demais que atuam em outras áreas hospitalares ${ }^{6}$.

No contexto atual, o cuidado em terapia intensiva hoje, mais do que no passado, tem sido balizado pela incorporação/utilização de novas tecnologias, abrindo novos horizontes e novas perspectivas para a melhoria da qualidade do trabalho/assistência e de vida dos sujeitos que cuidam e daqueles que são cuidados.

0 entendimento de que tecnologia é sinônimo de técnica não é uma unanimidade entre os autores que tratam da temática. Pensar a tecnologia e a técnica como coisas distintas talvez seja o ponto de partida para que possamos compreender por que a terapia intensiva é tão frequentemente entendida no discurso do senso comum como uma unidade capaz de se constituir em ameaça para o humano.

Basicamente dois fatores no início do século XVII cooperaram para o surgimento da tecnologia como uma aproximação da técnica com a ciência moderna. Primeiro, na Europa, o aparecimento de uma crença de que tudo poderia ser feito pelo homem a partir do conhecimento científico e, segundo, a ciência experimental passou a exigir, para seus experimentos, instrumentos com maior precisão, fabricados por cientistas com dotes artesanais, baseando-se em teorias científicas ${ }^{7}$.

Entretanto, a tecnologia como utilização das teorias científicas para a solução de problemas técnicos, conjugando ciência e tecnologia, foi perseguida durante muitos anos. Já no Renascimento, com o desenvolvimento da ótica de Galileu (século XV), ocorreu a integração entre técnica, tecnologia e ciência?

0 fato é que nos dias de hoje, talvez em função de vivermos numa época cujo contexto é marcado pelo avanço tecnológico nas diversas áreas do conhecimento humano, a tecnologia encontra-se no foco das discussões e tem sido enfaticamente citada pelos veículos de comunicação, algumas vezes de maneira otimista e, em outras, de maneira extremamente pessimista.

Com freqüência e equivocadamente, o termo tecnologia é utilizado para se referir apenas a um produto, geralmente uma máquina (tecnologias duras). Na terapia intensiva é assim que costumamos pensar a tecnologia: máquinas que parecem ser a alma, a espinha dorsal dessas unidades.

Esta forma de pensar a tecnologia da terapia intensiva está talvez relacionada às inúmeras máquinas, que, como as bombas de infusão, os monitores cardíacos, as camas eletrônicas, os ventiladores mecânicose muitas outras, parecem estar muito bem integradas e incorporadas nessas unidades, como se juntamente com elas tivessem nascidas ${ }^{8}$.

As máquinas que parecem dar sentido à terapia intensiva são hoje, no nosso entendimento, uma espécie de marco referencial, de forma que tem sido difícil pensar nessas unidades sem a sua presença. Isso nos faz pensar no seguinte questionamento: A suposta ameaça ao humano em terapia intensiva justifica-se apenas pelo predomínio do uso de tecnologias duras para cuidar?

Temos certeza de que se trata de uma questão cuja resposta não será encontrada ao final deste artigo, pois sabemos da necessidade de reflexões mais aprofundas acerca da temática e de enquadramento teórico e metodológico apropriados.

Assim, embora não seja objetivo deste artigo apresentar respostas para esta pergunta, acreditamos que poderemos trazer algumas importantes reflexões que poderão contribuir neste sentido. 


\section{DO DISCURSO DE HUMANIZAÇÃO À POLÍTICA PÚBLICA DE SAÚDE}

Denotativamente, humanismo poderá estar relacionado com a idéia, busca e preservação da dignidade humana. Neste sentido, qualquer tipo de ameaça à dignidade humana poderia perfeitamente ser entendido como atitude desumana.

Assim, toda e qualquer iniciativa que fosse tomada no sentido de se resgatar a dignidade humana "perdida" poderia ser entendida como uma iniciativa de humanização"

Com certa freqüência utilizamos no âmbito e entre os profissionais da saúde o termo "humanização". A nosso ver, o termo emerge num momento de grande apelo social, como um discurso, entendido equivocadamente como uma necessidade absoluta no contexto da civilização técnica7.

Ao refletirmos acerca da "humanização", podemos até partir da premissa de que os serviços de saúde precisam ser realmente humanizados, pois existem diversas situações, tanto no atendimento quanto nas condições de trabalho, que poderiam realmente ser consideradas "desumanizantes".

Alguns autores consideram, entretanto, que os profissionais de saúde, ao não se darem conta onde termina a máquina e onde começa o doente, transformam a sua relação com a máquina e o cuidado de enfermagem num ato mecânico, vendo o cliente uma extensão do aparato tecnológico ${ }^{10}$.

Precisamos entender que o fato de a equipe de enfermagem concentrar muito mais suas atenções nas situações críticas que requerem a utilização de tecnologias duras para cuidar pode realmente dificultar o controle de outras situações que expõem os clientes a condições vistas como desumanas.

Talvez seja por esta razão que Galian ${ }^{11}$ afirma que os grandes avanços científicos e técnicos no campo das ciências da saúde em geral vêm trazendo uma série de transformaç̧̃̃es, que têm o processo de desumanização como uma das principais conseqüências.

Não raramente, associa-se a idéia de impessoalidade, insensibilidade, automatização e mecanização ao entendimento de desumanização nas unidades de terapia intensiva ${ }^{6}$. Curiosamente, em que pese o fato de estas tecnologias terem sido criadas inicialmente para a terapia intensiva, a relação do homem com elas parece que é vista como "desumanizante" mais intensamente nestas unidades como se fossem as únicas a utilizá-las.

Entretanto, os baixos salários, a dificuldade na conciliação da vida familiar e profissional, a jornada de trabalho, muitas vezes dupla ou tripla, ocasionando sobrecarga de atividades e cansaço, e o contato constante com pessoas sob tensão raramente são trazidos para o debate sobre humanização.

Percebe-se que a valorização do doente/usuário do serviço de saúde como sujeito de direitos, capaz de exercer sua autonomia, passou a ser abordada somente a partir dos textos mais atuais (década de 1990 aos dias atuais), revelando uma idéia de "humanização" distinta da lógica da caridade, compreendendo-a como a possibilidade de dar condições para que o usuário seja participante ${ }^{12}$.

Em maio de 2000, o discurso de humanização ganha legitimidade, quando o governo, através do Ministério da Saúde,
Ihe dá status de política nacional a partir da edição de uma portaria que cria o Programa Nacional de "humanização" da Assistência Hospitalar (humaniza - SUS) ${ }^{13}$, onde o sujeito usuário dos serviços públicos de saúde é visto como um ser de direitos, e autônomo.

Mesmo considerando que no Programa do Governo Federal a palavra humanização aparece como um propósito a ser alcançado nos serviços de saúde, precisamos não cair na retórica que tem feito da idéia de humanização um discurso que tenta convencer sem, contudo, apresentar argumentações convincentes.

Quando perguntamos a alguém o que designa humanizar o cuidado em UTI é porque estamos subentendo que as práticas de cuidar nessas unidades são desumanas. Como resposta, podemos encontrar uma outra questão: É possível humanizar o que por natureza já é humano? Tal provocação não raramente é feita, revelando, inclusive entre aqueles que acreditam na idéia de humanização como um processo exeqüível, o quanto ainda está claro o que é humanização.

Geralmente empreendem-se esforços no sentido de propor iniciativas de "humanização" que visam exclusivamente transformar a assistência e as práticas de cuidar em UTI, perseguindo a valorização da "qualidade" do cuidado do ponto de vista técnico e do conforto, associada ao reconhecimento dos direitos do cliente, de sua subjetividade e referências culturais, a valorização do profissional e do cliente, além do diálogo intra e interequipes.

Desta forma é possível que o discurso de humanização nos desvie do nosso verdadeiro problema, que provavelmente não é a tecnologia, mas o enorme descuidado que hoje se observa nas unidades de terapia intensiva, mas que ainda preferimos chamar de desumanização, apontando a tecnologia da terapia intensiva como a principal responsável.

Assim, o desrespeito ao estatuto ético e aos compromissos nas relações entre os profissionais de enfermagem e seus clientes criam as condições de arbítrio e violência que levam ao desrespeito à condição e à dignidade humana, o que, em outras palavras, poderia ser entendido também como descuidado.

\section{CONSIDERAÇÕES FINAIS}

Podemos concluir que as reflexões acerca do cuidado de enfermagem em terapia intensiva deverão passar por uma contextualização mais aprofundada acerca dos conceitos de cuidado e da utilização de tecnologias nestas unidades.

Acreditamos que quaisquer que sejam as reflexões acerca das práticas de cuidar em terapia intensiva que porventura possam desconsiderar o contexto em que se dá o cuidado nestas unidades poderá incorrer em equívocos comprometedores capazes de se constituir em verdadeiros obstáculos epistemológicos.

Acreditamos oportuno que consideremos também os sentidos atribuídos à terapia intensiva, não só por parte dos profissionais de enfermagem, mas também por parte do usuário de nosso serviços.

Pensamos com estas iniciativas evitar limitações nas ações de cuidar, em que normalmente acabamos por colocar limites nas relações com os nossos clientes quando da existência de tecnologias que se colocam entre nós (profissionais e clientes).

Dar a devida atenção às máquinas não é necessariamente uma ação mecanicista. Entretanto, sob o nosso ponto de vista, 
cuidar de um cliente dependente da máquina é uma ação humana, ainda que tenhamos que pensar também nessa máquina e no sentido que ela tem para nós.

A grande diversidade tecnológica utilizada pela enfermagem nessas unidades para auxiliar na manutenção da vida é uma realidade que ao mesmo tempo encanta e assusta. Não obstante, apresenta aos profissionais que lidam com ela constantes desafios e questões, exigindo-lhes profundas e constantes reflexões acerca da sua aplicabilidade no cuidado.

Vale destacar que cuidar de máquinas não é um discurso teórico-prático tão absurdo, pois se ela em muitos casos mantém o cliente vivo, isso só é possível porque direta ou indiretamente cuidamos delas também. Programar as máquinas bem como ajustar seus parâmetros e alarmes e supervisionar seu funcionamento

\section{Referências}

1. Colliere MF. Invisible care and invisible woman as health careproviders. Int J Nurs Stud 1986; 23(2): 95- 112.

2. Borba SC. Multirreferencialidade na formação do "professorpesquisador"da conformidade à complexidade. Maceió(AL): Gráfica PSE; 1997.

3. Watson J. Nursing: the philosophy and science of caring. $2^{\mathrm{a}}$ ed. Colorado(USA): Associated University Press; 1985.

4. Merhy EE. Em busca da qualidade serviços de saúde: os serviços de porta aberta para a saúde e o modelo tecnoassistencial em defesa da vida (ou como aproveitar os ruídos do cotidiano dos serviços de saúde e colegiadamente reorganizar o processo de trabalho na busca da qualidade das ações de saúde. In: Oliveira LC, organizadora. Inventando a mudança na saúde. São Paulo(SP): Hucitec; 1994. p.117-60.

5. Coelho MJ. 0 socorro, o socorrido e o socorrer: cuidar/ cuidados em enfermagem de emergência. Rio de Janeiro(RJ) : EEAN/UFRJ; 1999.

6. Santoro DC. Situação do sistema de saúde no Brasil e os cuidados desenvolvidos nas unidades de terapia intensiva. Esc Anna Nery Rev Enferm 2001 ago; 5(2): 259-61.

7. Vargas M. História da técnica e da tecnologia. São Paulo(SP): UNESP; 1994. são para nós exemplos de cuidados para com elas e com os clientes que delas se beneficiam.

No entanto, ao fazermos isso, lançamos mão de conhecimentos técnicos e racionais que fundamentam nossas ações no trato com as máquinas, contribuindo para que essas ações sejam interpretadas como práticas desumanas, principalmente quando estes cuidados provocam no corpo do cliente sinais de dor, sofrimento e desconforto.

Assim, vale destacar que precisamos entender que os conceitos de cuidado de enfermagem e as definições que interessam para a profissão são dinâmicos e deverão variar de acordo com o contexto, com o movimento do mundo e, conseqüentemente, com as reconfigurações do humano. Portanto, o que se opõe ao cuidado é o descuidado, e isso de fato poderá estar ocorrendo e equivocadamente sendo denominado desumanização.

8. Silva RCL. 0 significado do cuidado em unidades de terapia intensiva e a (des)construção do discurso de humanização em unidades tecnológicas. [tese de doutorado]. Rio de Janeiro(RJ): Escola de Enfermagem Anna Nery/UFRJ; 2006.

9. Hiller E. Humanismo e técnica. Tradução de Carlos Lopes de Mattos. São Paulo(SP): EPU; 1973.

10. Nietsche EA. Tecnologia emancipatória: possibilidade para a práxis de enfermagem. ljuí (RS): Universidade de ljui; 2000.

11. Gallian MCD. A (re)humanização da medicina. São Paulo(SP): Escola Paulista de Medicina. Departamento de Psiquiatria /UNIFESP; 2000.

12. Pupulim JSL, Sawada NO. Exposição corporal do cliente no atendimento das necessidades básicas em UTI: incidentes críticos relatados por enfermeiras. Rev Latino-am Enfermagem [on-line] 2006 jul/ago; [citado 22 mar 2007]; 11(3): [aprox. 8 telas]. Disponível em: http://www.scielo.br

13. Ministério da Saúde (BR). Programa Nacional de Humanização da Assistência Hospitalar. Brasília (DF); 2000.

\section{Nota}

Utilizamos o termo tecnologia de terapia intensiva, pois entendemos que, assim como aconteceu com o pulmão de aço, as demais tecnologias (duras) que hoje se encontram disponíveis na terapia intensiva foram inicialmente pensadas para estes espaços, embora, nos dias de hoje, possam ser encontradas em diversos outros. 